$10^{\text {th }}$ International Conference of the International Institute for Infrastructure Resilience and Reconstruction (I3R2)

20-22 May 2014

Purdue University, West Lafayette, Indiana, USA

\title{
RFID Applied to Supply Chain Logistics in Disaster Recovery
}

\author{
Heng Wang, Bryan Hubbard, and Sarah Hubbard \\ Department of Building Construction Management, Purdue University
}

\begin{abstract}
The purpose of this paper is to review recent developments to use RFID (Radio Frequency Identification) for supply chain logistics in the construction industry and identify potential applications of this technology for disaster recovery in construction operations. Natural disasters, terrorist attacks, and extreme weather conditions can cause significant damage to local communities and disruptions to the local supply chain. The effective movement of resources during disaster recovery operations is critical in a postdisaster recovery environment. RFID technology has advanced to the level that the technology could be used to improve the supply chain preparedness, people, material and equipment locating and tracking, and corresponding billing operations in many industries. Current RFID technology could be used in the construction industry in areas to automate material tracking in off-site warehouse of construction firms or suppliers, to establish initial location of material received on construction sites, to track materials that are being shared and in common areas for multiple construction sites, to restock material in laydown or warehouses, to minimize material over-ordering with better tracking of quantity information, to reduce loss from theft and support site security measures, and to assist site equipment and fuel management.

Studies have shown that $3.1 \%$ of total construction costs could be saved after implementing RFID technology tagging and tracking materials on site and in warehouses. In the case of after-natural-disasters reconstruction, materials locating and tracking activities are highly valuable because disaster relief reconstruction site conditions are more challenging than regular construction site conditions. Reconstruction resources are often limited and difficult to move in and out. Significant construction cost savings can be achieved with RFI-enabled material tracking and locating systems. A review of the current technology provides many emerging applications of RFID technology for the broader construction industry. This paper examines direct applications of RFID for disaster relief reconstruction operations.
\end{abstract}

\section{INTRODUCTION}

RFID (Radio Frequency Identification) has been successfully demonstrated to improve supply chain logistics in manufacturing and transportation industries. This technology offers considerable promise in the construction industry, particularly for disaster recovery. Natural disasters, terrorist attacks, and extreme weather conditions can cause significant damage to local communities and disruptions to the local supply chain. The effective movement of resources during disaster recovery operations is critical in a post disaster recovery environment, and integrating RFID technology into the construction projects during the reconstruction activities holds significant promise. The paper reviews RFID applications in other sectors and assesses the potential for this technology in the construction industry, particularly during disaster recovery. Current RFID technology could be used in the construction industry in areas to automate material tracking in off-site warehouse of construction firms or suppliers, to establish initial location of material received on construction sites, to track materials that are being shared and in common areas for multiple construction sites, to restock material in laydown or warehouses, to minimize material overordering with better tracking of quantity information, to reduce loss from theft and support site security measures, and to assist site equipment and fuel management.

\section{BACKGROUND}

\subsection{Overview of Issues on a Disaster Reconstruction Site}

Disasters inflict high costs to society and its living environment. Impacts include loss of life and physical destruction of property. One of the most obvious examples of property destruction is seriously damaged or totally collapsed buildings. These buildings need to be demolished or reconstructed to provide shelter for those affected by the disaster. Huge amounts of debris or construction waste may result from a severe disaster, and the waste itself creates great difficulties during the reconstruction process as well as during disaster relief in general. The Hyogoken-Nambu earthquake in 1995 shook the highly developed urbanized area of Kansai, Japan; the result was 2 billion tons of debris (Hayashi \& Katsumi, 1996). It took the local government 2 years to clean up the debris which 
occurred simultaneously with reconstruction. The Wenchuan earthquake in 2008 leveled many rural areas in the southwest Sichuan Province in China and generated approximately 380 million tons of building waste (Xiao, Xie, \& Zhang, 2012). From the positive perspective, some of the material from the demolished or collapsed buildings could be recycled or reused. However, waste also created challenges. During the reconstruction process, the accumulation of huge amounts of building waste blocked traffic routes and created difficulties when laying down new material. Transporting people, material, and machinery around the waste also created difficulties. Waste may significantly hamper and slow down construction, limiting laydown areas and restricting access. During reconstruction after a natural disaster, there are not typical material laydown areas as there would be on a regular construction site. Aftershocks following an earthquake and landslides after flooding are common issues affecting the reconstruction workforce.

Reconstruction site management is much more difficult than a normal construction project. There is not a well-organized site laydown for material or a separate material storage area. The area also has numerous organizations to coordinate, including humanitarian organizations and government agencies. Access and routes to the damaged area and the construction sites need to remain clear for emergencies and life-saving activities.

\subsection{Supply Chain Management Role}

In a disaster scenario, in addition to loss of life and building losses, the supply chains for most businesses are usually incapacitated. Bonney (2011) presented a brief picture of the impact of Japan's earthquake and tsunami on the world's auto parts supply chain and how difficult it was to resume normal operations due to critical infrastructure failures such as power outages, road damage, and port congestion. The issue becomes how the necessary resources can get to the affected region as quickly as possible and how the damaged infrastructure should be demolished to repair the damaged roads and rebuild the collapsed bridges.

Supply chain management plays a significant role by using well-established management techniques and newly emerging technologies. Hale and Moberg (2005) proposed a decision process for secure site location as a way to improve supply chain preparedness. Decision cover location models (e.g., Toregas, Swain, ReVelle, \& Bergman, 1971; Minieka, 1970; Moore \& ReVelle, 1982; Lorena \& Lopes, 1994; Caprara, Toth, \& Fischetti, 2000) and FEMA's Disaster Management Guide for Businesses were adopted as the basis for this decisions process. Along the supply chain in a certain area, a few secure storage locations need to be identified for key material and equipment storage in preparation for potential disastrous events. Other studies propose different supply chain strategies. For example, Lodree and Taskin (2007) recommended a news vendor variant theory as a risk-management framework to prepare for and deal with disaster relief demand in the vendor's inventory planning.

More and more research looks at emerging technologies, such as RFID, that could have huge beneficiary impacts on construction project work.

Jaselskis, Anderson, Jahren, Rodriguez, \& Njos (1995) introduced the idea of RFID to the construction industry. They recognized that even the normal working conditions of a typical construction project involve harsh outdoor environments in which many construction processes have to be completed on time. They indicated that RFID technology could have a positive impact on improving normal construction work. RFID technology is a wireless communication technology, typically utilizing a tag and reader configuration. Circuit chips are imbedded in both tag and reader; the tag is attached to the subject, and the reader is supposed to read and identify the subject with corresponding prewritten information on the tag. Many technical aspects of RFID, such as active or passive tag, fixed or portable reader, radio wave length applicable, and so on, need to be carefully considered when setting up for a particular application. However, there are no requirements on line of sight, direct contact, or close proximity, and they are typically durable in all weather and harsh conditions; these capabilities provide RFID huge advantages over other technology like bar codes. Jaselskis et al. (1995) proposed conceptual ideas of taking RFID into the construction project processes such as labor, material receiving and tracking, concrete delivery, and quality control. But neither empirical data nor experimental results were offered or discussed. They did mention that the technology with different frequencies could be used in dangerous construction sites which were subject to landslides, earthquakes, and other natural disasters. A reconstruction site during a disaster relief period is by no means any safer; hence, it is a prime candidate for RFID application.

Later studies began to identify the specific processes and industrial areas that could utilize RFID for improvement, typically with pilot systems and field test studies as the application. Jaselskis and ElMisalami (2003) had a workshop to brainstorm ideas with construction practitioners and found applicable areas in spool tracking, mechanical machinery handling, material management, and field operations. They then engaged in two field test studies to obtain real data and actual performance of 
RFID on material identification and tracking processes in a normal construction project setting. These on-site tests, one on a power plant and the other on a refinery, were generally positive in terms of the benefits of RFID, particularly in terms of fast downloading of tracking information to the computer system without manual input. Questions to be solved were also identified, such as how to prevent replicate scanning and misses, how to avoid interference from metal nearby, etc. Despite the simplicity of the field tests and technical issues remaining, RFID technology showed promise for construction project improvement, especially in the material tracking area.

Song, Haas, Caldas, Ergen, and Akinci (2006) provided an overview of industrial construction processes and believed that automation of site material management and, more specifically, pipe spool tracking with RFID would result in huge potential improvement for these projects. The research team evaluated whether all materials being delivered automatically could be tracked while the truck drove through the gate of the site. They conducted their technical feasibility study and field tests in two phases with positive results. Some of the questions raised by Jaselskis and El-Misalam (2003) were no longer problems any more due to technological advances. RFID tags could be easily detected and read with metal surfaces nearby with some system configuration methods. The field tests essentially indicated that current RFID technology could automate the identification and tracking process for pipe spools with statistical significance. Provided time and further development of RFID technology, the trucks could go through the gate of the site and all shipping information of the delivery would be automatically entered into the computer.

A more sophisticated study conducted by Ergen, Akinci, and Sacks (2007) using a RFID prototype and GPS combination system on precast panel identification and tracking confirmed the technical feasibility of RFID technology. The study delineated high-level requirements, specifically, to minimize human input, to accurately locate and track equipment, and to eliminate the labor-intensive and error-prone manual identification and tracking system. Then, high-level technology requirements and functional prototypes were developed step by step. Field tests were conducted in the laydown yard of a precast plant where precast panels were temporarily stored and, in some cases, relocated multiple times before finally being shipped to the site according to site erection progress. The field test results showed a $60 \%$ success rate due to restricted accuracy of GPS and limited system integration. It was suggested that further research with more data and refinement of this system would validate it as a reliable automatic identification and tracking system.

Demiralp, Guven, and Ergen (2012) went on to study the potential cost savings along the supply chain and a potential RFID technology investment cost sharing ratio according to cost saving findings. The authors based their research on the precast and building industry along the supply chain. Three scenarios: manual, semiautomatic (SA) and full-automatic (FA) material tracking systems were developed along the same supply chain, including precast manufacture, shipping, and constructor on site. Probabilities of occurrence were obtained through interviews and previous studies. Simulation models were developed for multiply iterations. In normal construction cases, $3.1 \%$ of total construction costs could be saved after either SA or FA investments. While people were trying hard to reconstruct after natural disasters, limited resources were always a problem, and 3.1\% of the total cost of construction could make a big difference for the disaster afflicted communities.

As we see in the literature, automatic data collection technologies, in particular RFID, are attracting more and more attention from both industry and academia. Their technical capabilities are being tested and proven in an increasing number of studies. Based on previous research and an assessment of disaster recovery situations, RFID could be used in post disaster reconstruction as well as normal construction settings.

\section{APPLICATION OF RFID IN RECONSTRUCTION AND RESTORATION ACTIVITIES}

\subsection{Warehouse Material Management}

As was mentioned previously, reconstruction and restoration site conditions are far worse than typical construction conditions. Off-site warehousing for both constructor and vendors is a rational choice to make in face of the chaotic and hazardous reconstruction sites. Off-site warehouses can be equipped with RFID systems which scan materials; this information can be downloaded into a database efficiently and regularly without a significant investment of personnel hours. This process provides current information for both site reconstruction and home manufacturing information. As Ergen et al. (2007) tested in their study for both construction sites and manufacturing facilities, intensive data entry and time-consuming searches for needed materials either in warehouses or on construction sites can be minimized when availability information is collected via RFID readers. Accurate planning and scheduling based on current material availability minimizes schedule disruption using RFID on reconstruction sites. Manufacturing plants could adjust and arrange their operations based on 
demand and real-time off-site warehouse availability information. Providing this real-time availability information is achieved without the labor-intensive manual counting and data entry process, but instead utilizes scanning by RFID readers with automatic downloads into the computer database, time and resources would be saved which would increase the efficiency and timeliness of the reconstruction process.

\subsection{Movement of Material}

Given the limited number of access routes on reconstruction sites after disaster situations, it would be impossible for the reconstruction site team to have the time and space to finish the normal "kick and shake" process, which is the term that refers to manually locating and tracking material. RFID technology can increase the efficiency of tracking materials coming onto the job site, as well as tracking materials movements once on the site. As suggested and verified by Song et al. (2006), a truckload of material could be automatically recorded when the truck drives through a prearranged gate equipped with an RFID system. All materials properly tagged in the truck are instantly read by readers installed on the gates. Information in the tags can include basic material item name, the number on the plan, the order number, the manufacturer's name, the batch number, and so forth. This information about the incoming material is transferred to a site management computer system immediately. The reconstruction site management team would know right away what has arrived and what is needed for current reconstruction work. Once reconstruction for one project or one building is completed, any extra materials that are on site can be identified for movement to nearby sites. When the material exits the site through the RFID equipped gate, all information about the departing material will be automatically available for the site management team. As a result, materials are efficiently and instantly tracked. This application would be particularly useful when there is limited reconstruction site space and multiple projects have to share a common laydown area. RFID allows a reliable method for tracking what comes in and what leaves and the timing of these movements.

\subsection{Location}

Song, Haas, and Caldas (2007) presented a RFID and GPS system to find the location of material and equipment. Their study preliminarily established technical feasibility of accurately locating material via RFID- and GPS-configured systems on a regular construction site. With proper system configuration, materials' location on a reconstruction site using RFID system could be validated. On a reconstruction site, inventory of multiprojects is usually stored in a central location. A RFID system allows an accurate and up-to-date inventory of all materials. This inventory in a central location is accessible via a computer by many users and is automatically updated due to the GPS capabilities of the reader for RFID systems.

\subsection{Theft Prevention}

Activities following a disaster on reconstruction sites are often chaotic and disorganized, especially at the onset of reconstruction. People and materials are everywhere, and tracking is difficult. Thefts of building materials is quite common because local people have also been impacted by the disaster, and these people may or may not be the direct beneficiary of current reconstruction projects. Furthermore, materials may be scarce even if adequate funds are available.

An RFID system can be used to help prevent theft. Once the construction materials are properly tagged, an RFID system can be configured in such a way that security and alarm systems would be triggered when unauthorized material movement is detected. While further studies need to be conducted to identify specific system setup and operation, the technical capabilities of RFID make it useful for theft prevention on a reconstruction site.

\subsection{Quantity Ordering and Reordering}

RFID can be used to ensure instant information about material availability, as confirmed in off-site warehouse material management operations. With proper integration with contracting and logistics, information acquired by the RFID system from the reconstruction site, plus information regarding additional material that is required, can be combined, and the material that is needed can automatically be transferred via an automated procurement and logistics system. This allows automated quantity ordering and reordering, saving time and increasing efficiency.

\section{CONCLUSION}

Restoration and reconstruction in postdisaster reconstruction activities has many challenges, including disrupted transportation and logistics for materials, limited access to the site, and chaotic and hazardous site conditions. These conditions exist in addition to the challenges of a typical construction project. RFID technology has been proven successful in many industries and is being researched for construction applications. One of the applications that has not been fully explored but that offers significant promise is the application of RFID in postdisaster reconstruction. The capabilities of the RFID technologies offer significant promise to address many of the challenges of the postdisaster reconstruction site. Reconstruction site material 
movement and location, antitheft systems, and automated quantity ordering and reordering are all areas that RFID technology could have a significant impact during postdisaster reconstruction.

\section{REFERENCES}

Bonney, J. (2011). Disaster reaches the supply chain. Journal of Commerce, 12(13), 10.

Caprara, A., Toth, P., \& Fischetti, M. (2000). Algorithms for the set covering problem. Annals of Operations Research, 98(1-4), 353-371.

http://dx.doi.org/10.1023/A:1019225027893

Demiralp, G., Guven, G., \& Ergen, E. (2012). Analyzing the benefits of RFID technology for cost sharing in construction supply chains: A case study on prefabricated precast components. Automation in Construction, 24, 120-129. http://dx.doi.org/ 10.1016/j.autcon.2012.02.005

Ergen, E., Akinci, B., \& Sacks, R. (2007). Tracking and locating components in a precast storage yard utilizing radio frequency identification technology and GPS. Automation in Construction, 16(3), 354367. http://dx.doi.org/10.1016/j.autcon.2006.07.004

Hale, T., \& Moberg, C. R. (2005). Improving supply chain disaster preparedness $A$ decision process for secure site location. International Journal of Physical Distribution and Logistics Management, 35(3), 195-207. http://dx.doi.org/10.1108/ 09600030510594576

Hayashi, H., \& Katsumi, T. (1996). Generation and management of disaster waste. Soils and Foundations, 36(1), 349-358.

Jaselskis, E. J., Anderson, M. R., Jahren, C. T., Rodriguez, Y., \& Njos, S. (1995). Radio-frequency identification applications in construction industry. Journal of Construction Engineering and Management, 121(2), 189-196. http://dx.doi.org/ 10.1061/(ASCE)0733-9364(1995)121:2(189)

Jaselskis, E. J., \& El-Misalami, T. (2003). Implementing radio frequency identification in the construction process. Journal of Construction Engineering and Management, 129(6), 680-688. http://dx.doi.org/10.1061/(ASCE)07339364(2003)129:6(680)

Lodree, E. J., Jr., \& Taskin, S. (2008). An insurance risk management framework for disaster relief and supply chain disruption inventory planning. Journal of the Operational Research Society, 59(5), 674-684. http://dx.doi.org/10.1057/palgrave. jors.2602377

Lorena, L. A. N., \& Lopes, F. B. (1994). A surrogate heuristic for set covering problems. European Journal of Operational Research, 79(1), 138-150. http://dx.doi.org/10.1016/0377-2217(94)90401-4

Minieka, E. (1970). The m-center problem. SIAM Review, 12(1), 138-9.

Moore, G. C., \& ReVelle, C. (1982). The hierarchical service location problem. Management Science, 28(5), 775-780. http://dx.doi.org/10.1287/ mnsc.28.7.775

Song, J., Haas, C. T., Caldas, C., Ergen, E., \& Akinci, B. (2006). Automating the task of tracking the delivery and receipt of fabricated pipe spools in industrial projects. Automation in Construction, 15(2), 166-177. http://dx.doi.org/10.1016/ j.autcon.2005.03.001

Song, J., Haas, C. T., \& Caldas, C. H. (2007). A proximity-based method for locating RFID tagged objects. Advanced Engineering Informatics, 21(4), 367-376. http://dx.doi.org/10.1016/j.aei.2006. 09.002

Toregas, C., Swain, R., ReVelle, C., \& Bergman, L. (1971). The location of emergency service facilities. Operations Research, 19(6), 1363-1373. http://dx. doi.org/10.1287/opre.19.6.1363

Xiao, J., Xie, H., \& Zhang, C. (2012). Investigation on building waste and reclaim in Wenchuan earthquake disaster area. Resources, Conservation and Recycling, 61, 109-117. http://dx.doi.org/10.1016/j.resconrec.2012.01.012 